Bangladesh J. Sci. Res. 27 (2): 175-185, 2014 (December)

\title{
CHOICE OF SERVICE FACILITY FOR MATERNAL CARE AND ITS PROXIMATE CORRELATES
}

\author{
M. Sheikh Giash Uddin* and M. G. Kibria ${ }^{1}$ \\ Department of Statistics, Jagannath University, Dhaka-1100, Bangladesh
}

\begin{abstract}
The aim of this paper is to investigate the association between provision of maternal care services and its differentials. The study used data from Bangladesh Demographic and Health Surveys. The analysis revealed that the socio-economic status of women has positive impact on the likelihood of seeking antenatal care and delivering birth at a health facility. Women who have secondary and above education, the preference of facility delivery was also high. The likelihood of preferring private sector relative to public sector for delivery care has been increasing over time. The women of richest quintile are 3.5 times more likely to prefer delivery at public facility relative to home than the poorest quintile. The women with secondary and above education are 4 times more likely to deliver their child birth at public facility relative to home. This paper concludes that more attention should be given to the determinants of reproductive health, associated with their interactions such as service provision to reduce maternal morbidity and to achieve the MDG for maternal mortality.
\end{abstract}

Key words: Delivery Care, Service provision, Women education

\section{Introduction}

In Bangladesh, maternal mortality as well as associated maternal morbidity, is a serious public health concern. The current estimated maternal mortality ratio is 194 per 100,000 live births (NIPORT et al. 2012). Health services in Bangladesh are provided both through public and private sectors. Although public sector is the main source of family planning and reproductive health services, the private sector also contributes significantly to maternal and child health.

The Bangladesh Demographic and Health Surveys (BDHS) 2011 revealed that delivery in health facilities is 29 percent, while home deliveries were 71 percent (NIPORT et al., 2013). The Demographic and Health Surveys (DHS) conducted in other countries suggest that the private sector provides 51\% of health care in Sub Saharan Africa, 66\% in South-East Asia and as high as $79 \%$ in South Asia (Agus and Horiuchi 2012; Tey and Lai 2013). Factors that prevent women from receiving or seeking health care during pregnancy and childbirth include inadequate services, poverty, distance, lack of information, and cultural practices.

Corresponding author: <giash16@gmail.com>.1Quantificatin and MIS Management Sciences for Health (MSH), H\# 3, Road \# 23B, Gulshan-1, Dhaka-1212 
Non-institutional delivery is made up more than 80 per births in south-Asian countries like Bangladesh, Nepal and Afghanistan (UNICEF 2012). Factors that prevent women from receiving or seeking health care during pregnancy and childbirth include inadequate services, poverty, distance, lack of information, and cultural practices (UNICEF 2012). In Bangladesh studies have found that education, household socioeconomic status, and urban-rural residence are consistently significant predictors of service utilization (Amin et al. 2010).

The health care that a woman receives during pregnancy, at the time of delivery, and soon after delivery is important for the survival and well-being of both the mother and the child. The objective of this paper is to examine the association between choice of ANC and delivery care services and its differentials such as women's residence, economic position, educational status and access to BCC in Bangladesh.

Bangladesh Demographic and Health Survey (BDHS) (conducted in 1993-94, 1996-97, 19992000, 2004, 2007 and 2011) dataset was used in this study (Mitra et al. 1994, Mitra et al. 1997, NIPORT et al. 2001, NIPORT et al. 2005, NIPORT et al. 2009, NIPORT et al. 2013). BDHSs are a two-stage nationally representative survey which covers seven administrative divisions. At the first stage the primary sampling units were chosen from the Integrated Multi-Purpose Sample (IMPS) provided by the Bangladesh Bureau of Statistics based on census data. In BDHSs, there were 304 to 600 primary sampling units (PSUs), selected with probability proportional to size. After the selection of the primary sampling units, all households in each of the selected areas were mapped and listed. A systematic sample of households was then selected from these lists for each of the surveys. The analysis was done taking the most recent pregnancies and births occurred in the three years preceding the surveys. Therefore, sample births for this study were found 3926, $3665,4214,4126,3589$ and 4956 in last six surveys.

\section{Methods}

In order to assess different indicators over the period, the study used a number of statistical tools including bi-variate and multivariate analyses. Socio-economic status was assessed by constructing a household 'wealth index' based on principal components method and household asset. Bi-variate analysis was used to investigate the choice of utilization of reproductive health service provision (e.g., public, private, NGO etc) in Bangladesh. This study used multinomial logistic regression model. The dependent variables are place of delivery, source of delivery care services. Each of the variables recoded into nominal (polychotomous) variable with 3 categories. The place of delivery care recoded as $1=$ Public facility, $2=$ Private facility, $3=$ Home respectively. The use of health services provision is expected to be influenced by demographic (place of residence, geographical division), social (women's education), economic (wealth quintile) and programmatic (access to mass media and visit by field workers) factors. To control the influence of these variables, multivariate analysis with the main effects of selection of service provider and other variables was used to examine the preference of Bangladeshi women for selecting private sector for their health care services. 
A multinomial dependent variable required to make some notational adaptations. Let $\mathrm{J}$ represent the number of discrete categories of the dependent variable, where $J \geq 2$. Now, consider random variable $Z$ that can take on one of $J$ possible values. If each observation is independent, then each $Z_{\mathrm{i}}$ is a multinomial random variable. Once again, we aggregate the data into populations each of which represents one unique combination of independent variable settings. Since each observation records one of $\mathrm{J}$ possible values for the dependent variable, $\mathrm{Z}$, let y be a matrix with $\mathrm{N}$ rows (one for each population) and $\mathrm{J}-1$ columns. For each population, $\mathrm{y}_{\mathrm{ij}}$ represents the observed counts of the $j^{\text {th }}$ value of $Z_{i}$. Similarly, $\pi$ is a matrix of the same dimensions as $y$ where each element $\pi_{\mathrm{ij}}$ is the probability of observing the jth value of the dependent variable for any given observation in the $\mathrm{i}^{\text {th }}$ population.

The design matrix of independent variables, $\mathrm{X}$, contains $\mathrm{N}$ rows and $\mathrm{K}+1$ columns where $\mathrm{K}$ is the number of independent variables and the first element of each row, $x_{i 0}=1$, the intercept. Let $\beta$ be a matrix with $\mathrm{K}+1$ rows and $\mathrm{J}-1$ column, such that each element $\beta_{\mathrm{kj}}$ contains the parameter estimate for the $\mathrm{k}^{\text {th }}$ covariate and the $\mathrm{j}^{\text {th }}$ value of the dependent variable. For the multinomial logistic regression model, we equate the linear com ponent to the $\log$ of the odds of a $j^{\text {th }}$ observation compared to the $\mathrm{j}^{\text {th }}$ observation. That is, we will consider the $\mathrm{J}^{\text {th }}$ category to be the omitted or baseline category, where logits of the first $\mathrm{J}$ - 1 categories are constructed with the baseline category in the denominator. The model is given as

$\log \left(\frac{\pi_{i j}}{\pi_{i j}}\right)=\log \left(\frac{\pi_{i j}}{1-\Sigma_{j=1}^{j-1} \pi_{i j}}\right)=\sum_{k=0}^{K} x_{i k} \beta_{k j} ; i=1,2, \ldots . N$ and $j=1,2_{z} \ldots J-1$

Solving for $\pi_{\mathrm{ij}}$, we have

$$
\begin{aligned}
& \pi_{i j}=e^{\mathrm{R}_{k=0} \frac{x_{i k} \beta_{k j}}{1+\sum_{j=1}^{-1} e^{\sum_{k=2}^{K} x_{i k} \beta_{k j}}}}, j<1 \\
& \pi_{i j}=\frac{1}{1+\Sigma_{j=1}^{\gamma-1} e^{\sum_{i=\mathrm{e}}^{x_{i k} \beta_{k j}}}}
\end{aligned}
$$

\section{Results}

The analysis shows in Table 1 present the demographic and socio-economic background of sample respondents. The mean age of the respondents was about 25 years with a standard deviation 6.0. Twenty percent of sampled mothers were adolescent. Almost 20\% women lived in urban areas whereas $80 \%$ women lived in rural areas. The analysis reveals that the literacy rate among women is increasing. For example, 57 percent sampled women had no education in the 1993-4 survey 
whereas it was only 18 percent in 2011 . About $42 \%$ women mentioned that they had exposure to mass media in 1993-4 and it is increased to 63 percent in 2011.

Table 1: Background characteristics of sampled women by Survey year

\begin{tabular}{|c|c|c|c|c|c|c|c|}
\hline $\begin{array}{l}\text { Background } \\
\text { characteristics }\end{array}$ & & $1993-4$ & $1996-7$ & $1999-2000$ & 2004 & 2004 & 2011 \\
\hline \multirow[t]{5}{*}{ Age in 5-year groups } & $15-19$ & 17.7 & 21.3 & 22.2 & 21.9 & 21.2 & 19.9 \\
\hline & $20-24$ & 34.7 & 31.6 & 31.6 & 34.7 & 35.9 & 37.7 \\
\hline & $25-29$ & 25.7 & 26.5 & 24.6 & 22.6 & 24.3 & 25.3 \\
\hline & $30-34$ & 12.7 & 13.2 & 13.5 & 12.9 & 11.8 & 11.7 \\
\hline & 35 and above & 9.2 & 7.5 & 8.0 & 7.8 & 6.7 & 5.4 \\
\hline \multirow{2}{*}{$\begin{array}{l}\text { Type of place of } \\
\text { residence }\end{array}$} & Urban & 10.1 & 9.0 & 16.3 & 19.8 & 21.2 & 22.6 \\
\hline & Rural & 89.9 & 91.0 & 83.7 & 80.2 & 78.8 & 77.4 \\
\hline \multirow[t]{3}{*}{ Level of Education } & No education & 57.3 & 56.5 & 45.9 & 35.5 & 23.9 & 18.0 \\
\hline & Primary & 27.2 & 26.7 & 28.6 & 30.6 & 31.0 & 30.0 \\
\hline & Secondary & 15.5 & 16.8 & 25.5 & 34.0 & 45.1 & 52.0 \\
\hline \multirow[t]{5}{*}{ Wealth index } & Poorest & 22.5 & 20.9 & 23.2 & 25.0 & 21.1 & 22.9 \\
\hline & Poorer & 20.7 & 21.5 & 17.5 & 20.1 & 21.7 & 20.2 \\
\hline & Middle & 16.7 & 20.2 & 24.0 & 20.6 & 19.5 & 19.6 \\
\hline & Richer & 20.8 & 20.9 & 18.2 & 17.5 & 19.3 & 19.4 \\
\hline & Richest & 19.3 & 16.6 & 17.1 & 16.8 & 18.4 & 17.8 \\
\hline \multirow[t]{2}{*}{ Mass media access } & No & 58.0 & 55.5 & 56.8 & 32.5 & 37.6 & 36.6 \\
\hline & Yes & 42.0 & 44.5 & 43.2 & 67.5 & 62.4 & 63.4 \\
\hline \multirow[t]{2}{*}{ Mean age (SD) } & & 25.2 & 24.7 & $24.7(6.3)$ & 24.6 & 24.4 & 24.3 \\
\hline & & $(6.1)$ & $(6.1)$ & & $(6.2)$ & $(5.8)$ & (5.6) \\
\hline Total & & 3926 & 3665 & 4214 & 4126 & 3589 & 4956 \\
\hline
\end{tabular}

In 2011, nearly 44 percent of the urban women receive ANC from public sector, followed by private 45 percent and home 10.0 percent. On the other hand, nearly 46 percent of the rural women receive ANC from public sources, followed by private sources 35 percent and home 18 percent (Table 2). 
The analysis reveals that source of ANC service also varies by women's educational achievement. Forty four percent of the women with secondary and higher education rely on private sector whereas this proportion was 25 percent for women with no education. The well-off usually rely on the private sources for ANC services as compared to the poor. There is a significant increased choice of ANC service from private sources among richest women. It is important to note that more than a half (57.9 percent) of the women from richest quintile seeks ANC from private providers, while the same was only 17.5 percent for the poorest quintile.

The proportion of births delivered at a health facility is notably higher in urban areas as compared to the rural areas. Further, the facility delivery has increased significantly in the urban areas as compared to the rural areas.

Table 2: Source of antenatal care according to background characteristics, BDHS 2011

\begin{tabular}{lccccccc}
\hline \multirow{2}{*}{ Facility } & \multicolumn{2}{c}{ Place of residence } & \multicolumn{2}{c}{ Level of education } & \multicolumn{2}{c}{ Wealth quintiles } & \multirow{2}{*}{ Total } \\
\cline { 2 - 6 } & Urban & Rural & No education & Secondary & Poorest & Richest & \\
\hline Public & 43.7 & 46.1 & 46.3 & 45.2 & 51.1 & 36.1 & 45.4 \\
Private & 44.8 & 34.8 & 24.8 & 43.9 & 17.5 & 57.9 & 37.4 \\
NGO & 1.6 & 0.9 & 1.9 & 0.9 & 0.7 & 0.8 & 1.1 \\
Home & 9.5 & 18.0 & 26.7 & 9.8 & 30.5 & 5.1 & 15.8 \\
Others & 0.4 & 0.2 & 0.4 & 0.2 & 0.2 & 0.2 & 0.3 \\
\hline Total & 100.0 & 100.0 & 100.0 & 100.0 & 100.0 & 100.0 & 100.0 \\
\hline
\end{tabular}

In urban areas preference of public facility for giving birth has not been increased but the preference of private facility has increased significantly in last two decades. For example, in the year 1993-4 place of delivery at private facilities were only 9 percent in urban area whereas it has increased almost 3 times ( 25 percent) in 2011 (Table 3). In rural area the facility delivery (both public and private) among women has increased but no significant difference found between public facility delivery and private facility delivery.

The socio-economic status of women has positive impact on the likelihood of delivering at a health facility. Women's education is one of the most influential determinants of knowledge, attitudes, and behaviour. The educational attainment of a population is an important indicator of level of socioeconomic development as well as status in the society. Women with no education have no significant difference in choosing health facility for child birth. Women who have secondary and higher education, the preference of facility delivery has been increasing. Table-3 shows that in 1993-4, only 8 percent of secondary educated women received delivery service from public facility whereas it was almost double in 2011 . The proportion of selecting private facility 
Table 3. Percent distribution of market share of place of childbirth by respondent's socio-economic characteristics 1993-2011

\begin{tabular}{|c|c|c|c|c|c|c|c|}
\hline \multicolumn{2}{|c|}{ Socio-economic characteristics } & $1993-4$ & $1996-7$ & 1999-00 & 2004 & 2007 & 2011 \\
\hline \multicolumn{8}{|l|}{ Place of residence } \\
\hline \multirow[t]{4}{*}{ Urban } & Public Facility & 10.7 & 11.9 & 16.4 & 15 & 13 & 17.8 \\
\hline & Private Facility & 9.1 & 13.7 & 1.3 & 10.6 & 17 & 25.2 \\
\hline & NGO Facility & & & 9 & 1.6 & 3.7 & 6.3 \\
\hline & Home & 79.2 & 72.6 & 72.9 & 72.8 & 66.1 & 50.5 \\
\hline \multirow[t]{4}{*}{ Rural } & Public Facility & 1.0 & 1.8 & 3.5 & 5.2 & 6.5 & 10.1 \\
\hline & Private Facility & 0.6 & 0.8 & 0.3 & 2.2 & 5.5 & 12.2 \\
\hline & NGO Facility & & & 1.3 & 0.5 & 0.8 & 0.6 \\
\hline & Home & 98.2 & 96.8 & 94.7 & 91.8 & 86.9 & 77.0 \\
\hline \multicolumn{8}{|l|}{ Level of education } \\
\hline \multirow[t]{4}{*}{ No education } & Public Facility & 0.5 & 1.2 & 3.1 & 1.8 & 1.8 & 4.9 \\
\hline & Private Facility & 0.1 & 0.1 & 0.2 & 0.8 & 1.9 & 4.7 \\
\hline & NGO Facility & & & 0.3 & 0.2 & 0.4 & 1.6 \\
\hline & Home & 99.3 & 98.2 & 96.5 & 97.3 & 95.9 & 88.8 \\
\hline \multirow[t]{4}{*}{ Secondary and above } & Public Facility & 8.6 & 8.9 & 12.6 & 14.1 & 13.3 & 16.0 \\
\hline & Private Facility & 7.4 & 9.9 & 1 & 8.8 & 15.2 & 22.7 \\
\hline & NGO Facility & & & 8.2 & 1.2 & 2.7 & 2.4 \\
\hline & Home & 83.7 & 80.2 & 77.8 & 75.7 & 68.3 & 58.7 \\
\hline \multicolumn{8}{|l|}{ Wealth quintiles } \\
\hline \multirow[t]{4}{*}{ Poorest } & Public Facility & 0.2 & 0.8 & 2.2 & 2.1 & 3.6 & 6.9 \\
\hline & Private Facility & & & 0.4 & 0.2 & 2.2 & 2.8 \\
\hline & NGO Facility & & & 0.1 & 0.2 & 0.5 & 0.3 \\
\hline & Home & 99.7 & 98.8 & 96.9 & 97.3 & 93.7 & 90.1 \\
\hline \multirow[t]{4}{*}{ Richest } & Public Facility & 7.3 & 8.4 & 18.1 & 20.2 & 17.5 & 19.1 \\
\hline & Private Facility & 6.6 & 9.9 & 1.4 & 15.4 & 26.6 & 35.5 \\
\hline & NGO Facility & & & 12.5 & 2 & 4.4 & 5.1 \\
\hline & Home & 85.2 & 79.9 & 67.6 & 62.4 & 51 & 40.1 \\
\hline
\end{tabular}


was higher than public facility for giving birth among women who have secondary and higher education.

It is also important to note that the proportion of birth delivered at private facilities has increased sharply among the well-off women from 6.6 percent in 1993-94 to 35.8 percent in 2011. In contrast, home delivery has decreased significantly among the well-off from 85.2 percent in 1993-94 to 40 percent in 2011. Almost 36 percent of the women from the richest quintile deliver in a private facility in 2011, while the same is only 2.8 percent among the poor quintile. However, it can be concluded that the poor are still preferred to deliver at home, while the private sector plays an important role in providing delivery care to the well-off. With respect to Health, Population and Nutrition Sector Development Program (HPNSDP) 2016 target on reducing the rich-poor gap in facility delivery.

The result indicates that Bangladesh has made some progress in reducing the wide gap between the poorest and the richest in use of facilities for delivery. For example, in 2011 it is observed that the proportion of facility delivery among poorest quintile was 9.9 percent and 59.8 among the highest quintile whereas in 1993-4 the proportion was only 0.2 percent and 13.9 percent respectively. Twenty percent of women who have access to mass media chose private facility and 15 percent of them chose public facility to give birth in 2011 while in 1993-4 the rates were 3.2 percent and 3.9 percent. Moreover, women who have no mass media access are relied on only home delivery for their child birth (Table 4).

Table 4. Percent distribution of market share of place of childbirth by respondent's access to mass media 1993-2011

\begin{tabular}{|c|c|c|c|c|c|c|c|}
\hline \multirow{2}{*}{\multicolumn{2}{|c|}{$\begin{array}{l}\text { Background characteristics } \\
\text { Mass media access }\end{array}$}} & \multirow{3}{*}{$\begin{array}{c}1993-4 \\
3.9\end{array}$} & \multirow{3}{*}{$\begin{array}{c}1996-7 \\
4.6\end{array}$} & \multirow{3}{*}{$\begin{array}{c}1999-00 \\
9.5\end{array}$} & \multirow{3}{*}{$\begin{array}{c}2004 \\
9.2\end{array}$} & \multirow{3}{*}{$\begin{array}{c}2007 \\
9.8\end{array}$} & \multirow{3}{*}{$\begin{array}{r}2011 \\
14.4\end{array}$} \\
\hline & & & & & & & \\
\hline \multirow[t]{4}{*}{ Yes } & Public Facility & & & & & & \\
\hline & Private Facility & 3.2 & 4.0 & 1.0 & 5.4 & 11.3 & 20.4 \\
\hline & NGO Facility & & & 5.4 & 1.0 & 2.1 & 2.5 \\
\hline & Home & 92.4 & 90.4 & 83.8 & 84.3 & 76.4 & 62.4 \\
\hline \multirow[t]{4}{*}{ No } & Public Facility & 0.6 & 1.2 & 2.7 & 2.8 & 4.7 & 7.3 \\
\hline & Private Facility & 0.3 & 0.2 & 0.1 & 0.7 & 2.4 & 6 \\
\hline & NGO Facility & & & 0.5 & 0.1 & 0.2 & 0.8 \\
\hline & Home & 99.0 & 98.0 & 96.6 & 96.0 & 92.5 & 85.8 \\
\hline \multicolumn{2}{|c|}{ Total } & 100.0 & 100.0 & 100.0 & 100.0 & 100.0 & 100 \\
\hline
\end{tabular}




\section{Choice of delivery care service: Multinomial logistic regression analysis}

Public facility to Home: The regression analysis shows that in 2011, the likelihood of preferring delivery at public facility relative to home delivery would be expected to 4.4 times higher than 1996 where other variables in the model are held constant. In other words, in 2011 women are more likely to prefer public facility relative to home delivery than 1996 (Table 5). The women of richest quintile are 3.5 times more likely to prefer delivery at public facility relative to home than

Table 5. Multinomial Logistic Regression dependent variable is market share delivery facility (Home is the most frequently preferred place is the reference group)

\begin{tabular}{|c|c|c|c|c|}
\hline Variables & & $\begin{array}{l}\text { Public facility to home } \\
\text { (OR and } 95 \% \mathrm{CI} \text { ) }\end{array}$ & $\begin{array}{l}\text { Private facility to home } \\
\text { (OR and } 95 \% \mathrm{CI})\end{array}$ & $\begin{array}{l}\text { Public facility to Private } \\
\text { (OR and } 95 \% \mathrm{CI})\end{array}$ \\
\hline \multirow[t]{5}{*}{ Survey year } & 1996-7 (RC) & 1.00 & 1.00 & 1.00 \\
\hline & $1999-2000$ & $2.61(2.15-3.16)$ & $0.20(0.13-0.29)$ & $12.07(7.48-19.49)$ \\
\hline & 2004 & $2.07(1.70-2.52)$ & $1.20(0.96-1.50)$ & $1.81(1.29-2.54)$ \\
\hline & 2007 & $2.50(2.06-3.04)$ & $2.42(1.96-2.99)$ & $1.06(0.76-1.47)$ \\
\hline & 2011 & $4.38(3.64-5.27)$ & $5.69(4.68-6.92)$ & $0.80(0.59-1.00)$ \\
\hline \multirow{2}{*}{$\begin{array}{l}\text { Place of } \\
\text { residence }\end{array}$} & Urban (RC) & 1.00 & 1.00 & 1.00 \\
\hline & Rural & $0.42(0.38-0.47)$ & $0.53(0.47-0.60)$ & $0.77(0.65-0.91)$ \\
\hline \multirow[t]{6}{*}{ Division } & Barisal (RC) & 1.00 & 1.00 & 1.00 \\
\hline & Chittagong & $0.92(0.74-1.15)$ & $0.81(0.62-1.05)$ & $1.26(0.86-1.86)$ \\
\hline & Dhaka & $1.27(1.03-1.57)$ & $1.27(0.98-1.63)$ & $1.02(0.70-1.48)$ \\
\hline & Khulna & $2.07(1.65-2.60)$ & $2.03(1.55-2.66)$ & $1.08(0.73-1.60)$ \\
\hline & Rajshahi & $1.58(1.27-1.97)$ & $1.44(1.11-1.87)$ & $1.08(0.74-1.59)$ \\
\hline & Sylhet & $1.14(0.87-1.48)$ & $0.84(0.60-1.16)$ & $1.77(1.10-2.85)$ \\
\hline \multirow{3}{*}{$\begin{array}{l}\text { Level of } \\
\text { education }\end{array}$} & No education (RC) & 1.00 & 1.00 & 1.00 \\
\hline & Primary & $1.79(1.55-2.06)$ & $1.68(1.36-2.07)$ & $1.01(0.75-1.38)$ \\
\hline & Secondary & $4.03(3.51-4.63)$ & $5.14(4.23-6.25)$ & $0.85(0.64-1.12)$ \\
\hline \multirow{5}{*}{$\begin{array}{l}\text { Wealth } \\
\text { index }\end{array}$} & Poorest (RC) & 1.00 & 1.00 & 1.00 \\
\hline & Poorer & $0.95(0.79-1.14)$ & $1.60(1.22-2.09)$ & $0.59(0.40-0.86)$ \\
\hline & Middle & $1.20(1.01-1.42)$ & $2.03(1.56-2.63)$ & $0.61(0.42-0.87)$ \\
\hline & Richer & $1.83(1.55-2.17)$ & $3.41(2.65-4.40)$ & $0.51(0.36-0.72)$ \\
\hline & Richest & $3.48(2.92-4.15)$ & $9.99(7.73-12.91)$ & $0.36(0.26-0.52)$ \\
\hline \multirow{2}{*}{$\begin{array}{l}\text { Mass media } \\
\text { access }\end{array}$} & No (RC) & 1.00 & 1.00 & 1.00 \\
\hline & Yes & $1.39(1.24-1.55)$ & $1.49(1.28-1.74)$ & $0.87(0.70-1.08)$ \\
\hline
\end{tabular}

the poorest quintile. The women with secondary and above education are 4 times more likely to deliver their child birth at public facility relative to home. Similarly, those who have mass media access are 1.4 times higher likelihood to prefer public facility delivery relative home than who 
have no access. Women in rural areas are 58 percent less likely to give birth in public facility relative to home than women in urban areas.

Private facility to Home: Like public facility it is also found that the likelihood of preferring delivery at private facility relative to home delivery would be expected to 5.7 times higher in 2011 than 1996. There is significantly increasing trends of private facility in last two surveys. Women in rural areas are 45 percent less likely to private facility delivery relative to home than women in urban areas. The women with secondary and above education are 5.9 times more likelihood to deliver their child birth at private facility relative to home. The women of richest quintile are 10 times more likely to prefer delivery at private facility relative to home than the poorest quintile. Similarly, those who have mass media access are 1.5 times higher likelihood to prefer private facility delivery relative home than who have no access. The women in Khulna and Rajshahi divisions are also more likely to prefer private facility to home than Barisal division.

Public facility to Private facility: The analysis shows that in 2011, the likelihood of preferring delivery at public facility relative to private facility would be expected to 20 percent less than in 1996. The findings also indicate that the preference of public facility for child birth is declining over time as compare to private facility.

The women of richest quintile were 64 percent less likely to prefer delivery at public facility relative to private than the poorest quintile. Women in rural areas are 23 percent less likely to give birth in public facility relative to private facility than women in urban areas.

\section{Discussions}

This study aimed at identifying the factors affecting the choice of maternal care services in Bangladesh. The current study shows a consistently strong relationship between the choice of delivery care service and the education of the respondent, their residence, and economic status. The findings of this study imply that the public sector has an important role to play in delivery care for the poor. The results suggest that the private sector's receptiveness to changing consumer preferences was enabling rural women in the lowest quintiles to switch to the private sector. As the private sector expands, the public sector must increasingly target low income women living in rural areas.

The facility where a woman receives ANC and delivery care influences the quality of care received. Information on the different sources also assists policymakers with decisions on how to allocate resources. The results revealed that women in urban areas and women in the highest wealth quintile are more likely to receive delivery assistance from the private sector. There is very sparse evidence on socioeconomic differentials in the quality of antenatal care in developing countries (Navaneetham and Dharmalingam, 2002; Ahmed et al., 2000). Education is significantly associated with utilization of maternal health services. Our study showed that a significant portion of women with secondary and above education preferred private facility for delivery. It is likely that more educated women seek higher quality services and have greater ability to use health care inputs to ensure better health. The choice of private service relative to public facility is significant 
among wealthiest women rather than poor women. The reason of choosing private facility might be due to the availability, accessibility and affordability of the women.

We have also shown that mother's education, residence, mass media access and socioeconomic status were important independent factors in determining the choice of delivery place. A study also found maternal education among women was the important independent factors in determining the place of delivery in Nepal (Bolam et al. 1998). Yanagisawa et al. (2006) also documented that woman who had at least 7 years of school attendance being six times more likely to deliver babies at a health facility than those who did not attend. Wealth quintiles and sociocultural factors play a major role in the choice of place of delivery. Limited access in rural areas, mainly caused by lack of money and long distances to healthcare facilities, is particularly a problem. Moreover, mid-wife-assisted home births could possibly improve the safety of the mother and the newborn.

\section{Conclusion}

In Bangladesh maternal health care need is one of the nation's public health priorities. This study reveals the choices and differentials of maternal services in Bangladesh. The findings showed facility deliveries are increasing but still low as expected to national goal (percentage of births attended by skilled providers would be $50 \%$ by 2015 ). It is important to note facility delivery is increasing more quickly in private sector facilities than in public sector facilities. This increment is heavily towards the higher educated and economically better off sections of the community. The analysis showed that maternal education, wealth quintile mass media access and place of residence significantly affect on choice of health facility.

The overall findings seem to suggest the correlates of maternal care need to address in developing suitable program to meet the MDG 5. Given the low institutional delivery and high maternal mortality, there is a need to target the groups who do not use health services for delivery and address the barriers that exist.

\section{References}

Agus Y, Horiuchi S. 2012. Factors influencing the use of antenatal care in rural West Sumatra, Indonesia. BMC Pregnancy Childbirth; 12:9.

Ahmed SM, Adams AM, Chowdhury M, Bhuiya A. (2000) Gender, socioeconomic development and health seeking behavior in Bangladesh. Soc Sci Med; 51: 361-371.

Amin R. , N. M. Shah, and S. Becker. 2010. "Socioeconomic factors differentiating maternal and child health-seeking behavior in rural Bangladesh: a cross-sectional analysis," International Journal for Equity in Health, 9 (9): 2010.

Bolam A, Manandhar DS, Shrestha P, Ellis M, Malla K, Costello AM. 1998. Factors affecting home delivery in the Kathmandu Valley, Nepal. Health Policy

Plan.;13(2): 152-8. 
Mitra, S. N., M. N. Ali, S. Islam, A. R. Cross, and T. Saha. 1994. Bangladesh Demographic and Health Survey, 1993-1994. Dhaka, Bangladesh, and Calverton, Maryland: National Institute of Population Research and Training (NIPORT), Mitra and Associates, and Macro International Inc.

Mitra, S. N., A. A1-Sabir, A. R. Cross, and K. Jamil. 1997. Bangladesh Demographic and Health Survey,1996-1997. Dhaka, Bangladesh, and Calverton, Maryland, USA: National Institute of Population Research and Training (NIPORT), Mitra and Associates, and Macro International Inc.

National Institute of Population Research and Training (NIPORT), Mitra and Associates, and ORC Macro.2001.Bangladesh Demographic and Health Survey 1999-2000. Dhaka, Bangladesh, and Calverton, Maryland: NIPORT, Mitra and Associates, and ORC Macro.

National Institute of Population Research and Training (NIPORT), Mitra and Associates, and ORC Macro.2005. Bangladesh Demographic and Health Survey 2004. Dhaka, Bangladesh, and Calverton, Maryland: NIPORT, Mitra and Associates, and ORC Macro.

National Institute of Population Research and Training (NIPORT), Mitra and Associates, and Macro International. 2009. Bangladesh Demographic and Health Survey 2007. Dhaka, Bangladesh, and Calverton, Maryland, USA: NIPORT, Mitra and Associates, and Macro International.

National Institute of Population Research and Training (NIPORT), MEASURE Evaluation, and icddr,b. 2012. Bangladesh Maternal Mortality and Health Care Survey 2010.Dhaka, Bangladesh: NIPORT, MEASURE Evaluation, and icddr,b.

National Institute of Population Research and Training (NIPORT), Mitra and Associates, and ICF International. 2013. Bangladesh Demographic and Health Survey 2011. Dhaka, Bangladesh and Calverton, Maryland, USA: NIPORT, Mitra and Associates, and ICF International.

Navaneetham K, Dharmalingam A. 2002. Utilization of maternal health care services in Southern India. Soc Sci Med; 55: 1849-1869.

Tey NP and Lai SL. 2013.Correlates of and Barriers to the Utilization of Health Services for Delivery in South Asia and Sub-Saharan Africa. The Scientific World Journal: 2013: (423403), 11

UNICEF. 2012. "Maternal and newborn health," Young Child Survival and Development, The United Nations Children's Fund (UNICEF), 2012.

Yanagisawa S, Oum S, Wakai S. 2006. Determinants of skilled birth attendance in rural Cambodia. Trop Med Int Health.;11(2): 238 - 51.

(Manuscript received on 26 November, 2014; revised on 21 December, 2014) 